\title{
Organic Acids Improve Growth Performance with Potential Regulation of Redox Homeostasis, Immunity, and Microflora in Intestines of Weaned Piglets
}

\author{
Xin-Dong Xiang ${ }^{1,+}$, Zhang-Chao Deng ${ }^{1,+}$, You-Wei Wang ${ }^{2,+}$, Hua Sun ${ }^{1}$, Li Wang ${ }^{3,4, *}$, Yan-Ming Han ${ }^{5}$, \\ Yuan-Yuan Wu ${ }^{5}$, Jian-Gao Liu ${ }^{6,7, *}$ and Lv-Hui Sun ${ }^{1, *}$
}

1 Hubei Hongshan Laboratory, College of Animal Science and Technology, Huazhong Agricultural University, Wuhan 430070, China; xiangxindong.hzau.edu.cn@webmail.hzau.edu.cn (X.-D.X.); dengzc@webmail.hzau.edu.cn (Z.-C.D.); huasun@webmail.hzau.edu.cn (H.S.)

2 Hubei Key Laboratory of Embryonic Stem Cell Research, School of Basic Medicine Science, Hubei University of Medicine, Shiyan 442000, China; 6wyw6@163.com

3 Institute of Animal Science, Guangdong Academy of Agricultural Sciences, Guangzhou 510640, China

4 Ministry of Agriculture Key Laboratory of Animal Nutrition and Feed Science in South China, Guangzhou 510640, China

5 Trouw Nutrition, 773811 Amersfoort, The Netherlands; Yanming.Han@trouwnutrition.com (Y.-M.H.); Yuanyuan.Wu@trouwnutrition.com (Y.-Y.W.)

6 Guangzhou Liuhe Feed Company Limited, Guangzhou 511400, China

7 Key Laboratory of Feed and Livestock and Poultry Products Quality \& Safety Control, Ministry of Agriculture, Chengdu 610110, China

check for
updates

Citation: Xiang, X.-D.; Deng, Z.-C.; Wang, Y.-W.; Sun, H.; Wang, L.; Han, Y.-M.; Wu, Y.-Y.; Liu, J.-G.; Sun, L.-H. Organic Acids Improve Growth

Performance with Potential

Regulation of Redox Homeostasis, Immunity, and Microflora in Intestines of Weaned Piglets. Antioxidants 2021, 10, 1665. https:// doi.org/10.3390/antiox10111665

Academic Editor: Peter F. Surai

Received: 15 September 2021

Accepted: 21 October 2021

Published: 22 October 2021

Publisher's Note: MDPI stays neutral with regard to jurisdictional claims in published maps and institutional affiliations.

Copyright: (c) 2021 by the authors. Licensee MDPI, Basel, Switzerland. This article is an open access article distributed under the terms and conditions of the Creative Commons Attribution (CC BY) license (https:// creativecommons.org/licenses/by/ $4.0 /)$.
* Correspondence: wangli1@gdaas.cn (L.W.); liujg2@newhope.cn (J.-G.L.); lvhuisun@mail.hzau.edu.cn (L.-H.S.)

+ These authors contributed equally to this work.

\begin{abstract}
The objective of this study is to evaluate the effects of organic acids on piglet growth performance and health status. A total of 360 weanling pigs $(5.3 \pm 0.6 \mathrm{~kg})$ were randomly allotted to 3 treatment groups with 12 replicates of 10 pigs/pen. Piglets were fed the same basal diet and given either water (control) or water plus 2.0 L/Ton organic acid (OA) blends, such as OA1 or OA2, respectively, for 7 weeks. Compared to the control, OA1 and OA2 improved growth performance and/or reduced the piglets' diarrhea rate during the various periods and improved small intestinal morphology at days 14 and/or 49. OA1 and OA2 also increased serum CAT and SOD activities and/or T-AOC and, as expected, decreased MDA concentration. Moreover, at day 14 and/or day 49, OA1 and OA2 increased the jejunal mRNA levels of host defense peptides (PBD1, PBD2, NPG1, and NPG3) and tight junction genes (claudin-1) and decreased that of cytokines (IL-1 $\beta$ and $I L-2)$. Additionally, the two acidifiers regulated the abundance of several cecum bacterial genera, including Blautia, Bulleidia, Coprococcus, Dorea, Eubacterium, Subdoligranulum, and YRC2. In conclusion, both of the organic acid blends improved piglet growth performance and health status, potentially by regulating intestinal redox homeostasis, immunity, and microflora.
\end{abstract}

Keywords: weanling pigs; acidifiers; performance; redox status; immunity; gut microbiota

\section{Introduction}

Early weanling piglets are exposed to a variety of stress factors, such as psychological, nutritional, and environmental stress [1-3], resulting in induced growth retardation, diarrhea, morbidity, and mortality [4,5]. These metabolic disorders, induced by weanling stress, are related to the impairment of inflammatory response, redox balance, intestinal health, and microbiota homeostasis [6-8]. Therefore, it is of great significance to develop effective strategies for the improvement of the piglets' health during the weaning period.

Organic acids have long been recognized as one of the alternative choices to replace antibiotics in diets for weanling pigs [9]. It can reduce diarrhea and improve the nutrient digestibility and growth performance of piglets, which are mainly related to improving 
gastrointestinal tract health, including decreasing digesta $\mathrm{pH}$ values and pathogenic bacteria and maintaining the balance of microflora [10-12]. Specifically, formic acid and its salts have an antimicrobial ability and can reduce digesta $\mathrm{pH}$, thus improving digestive enzyme activities [12]. As preservative and antifungal agents, acetic and propionic acids play important roles, mainly as antibacterial agents and against molds, respectively [13]. These short-chain fatty acids also play important roles in the regulation of the immune system and microbiota homeostasis [14-16]. Lactic acid is also widely applied to inhibit the growth of key microbial pathogens [13]. Sorbic acid is a long chain unsaturated fatty acid that has a strong antimicrobial activity by suppressing the activities of key enzymes and transport systems and inducing a proton flux into the cells of bacteria [17]. Citric acid is a well-studied organic acid in weanling pigs that has an antibacterial capacity and can act as an energy supply via entering the tricarboxylic acid cycle [9].

Since various organic acids play different roles in maintaining the health status of gastrointestinal tract health, the two organic acid blend products were developed based on their unique advantages. The objective of the current study is to evaluate the effects of the two acidifier products, organic acid 1 (OA1) and organic acid 1 (OA2), on weanling piglet growth performance, redox homeostasis, and intestinal health status.

\section{Materials and Methods}

\subsection{Piglets, Dietary Treatments, and Sample Collections}

The animal protocol was approved by the Institutional Animal Care and Use Committee of Huazhong Agricultural University, China. A total of 360 eighteen-day-old Pig Improvement Company (PIC) weanling pigs $(5.3 \pm 0.6 \mathrm{~kg}$ ) were randomly allotted into 3 dietary treatment groups with 12 replicates of 10 pigs/pen ( 5 barrows and 5 gilts). A basal diet with typical commercial ingredients was prepared (Table S1). The two commercial organic acids blends were produced by Nutreco N.V. (Amsterdam, Netherlands). The piglets from the three groups were given drinking water (Control) or drinking water with added OA1 (mainly containing formic acid $(31.0 \%)$, ammonium formate $(23.0 \%)$, and acetic acid $(8.3 \%)$, with water as a solvent) or OA2 (mainly containing formic acid (13.0\%), ammonium formate $(19.0 \%)$, acetic acid $(10.0 \%)$, propionic acid $(13.0 \%)$, sorbic acid $(0.5 \%)$, lactic acid $(1.0 \%)$, and citric acid $(0.5 \%)$, with water as a solvent) at $2.0 \mathrm{~L} /$ Ton. The final $\mathrm{pH}$ of the water was 8.17, 4.21, and 4.88 in the groups of Control, OA1, and OA2, respectively. Feed and water were given ad libitum during the experimental period. A three-phase feeding program was followed, with weanling 1-14 days post-weanling, 15-28 days postweanling, 29-49 days post-weanling as Phase 1, Phase 2, and Phase 3, respectively. Feed intake, diarrhea, and mortality were recorded daily, and body weight was measured at day 14 post-weanling and day 49 post-weanling. On the last day of Phase 1 and Phase 3, 6 male piglets per treatment, at average body weight from different replicates, were selected and slaughtered. Blood, small intestinal, and cecum digesta samples were collected for biochemical, histologic examination, and microbial analyses $[18,19]$. Briefly, the serum was prepared by centrifugation at $4{ }^{\circ} \mathrm{C}$ at $1000 \times \mathrm{g}$ for $15 \mathrm{~min}$ and stored at $-80^{\circ} \mathrm{C}$ before use. The small intestinal segments were perfused with ice-cold isotonic saline, minced with surgical scissors, divided into aliquots, and stored at $-80^{\circ} \mathrm{C}$ until analysis.

\subsection{Redox Status, Digestive Enzyme Activity, and Histologic Analysis}

Total antioxidant capacity (T-AOC), glutathione peroxidase (GPX), catalase (CAT) and superoxide dismutase (SOD) activities and malondialdehyde (MDA) and protein carbonyl (PC) concentrations were determined by their specific assay kits (A015-1-2, A005-1-2, A0071-1, A001-3-2, A003-1-2, and A087-1-2) from the Nanjing Jiancheng Bioengineering Institute of China. Protein concentration was analyzed by the bicinchoninic acid assay [19]. Jejunal chyme lipase, $\alpha$-amylase, and neutral protease activities were measured by their specific assay kits (A054-1, C016-1, A080-3-1; Nanjing Jiancheng Bioengineering Institute, Nanjing, China) [20]. Small intestinal histopathology and morphology were analyzed as previously described [18]. Briefly, the duodenum, jejunum, and ileum tissues were washed with saline, 
fixed in $10 \%$ neutral buffered formalin, embedded in paraffin, sectioned at $5 \mu \mathrm{m}$, and then stained with hematoxylin and eosin. All slides were examined by a microscope.

\subsection{Real-Time q-PCR Analyses}

Real-time q-PCR analyses of the jejunum samples were carried out as previously described [18]. Briefly, total RNA was isolated from the jejunum of 6 piglets from each group, and the RNA samples were quantified and qualified by a NanoDrop spectrophotometer. The mRNA levels of cytokines genes (Interleukin (IL)-1 $\beta, I L-2$ and IL-6), host defense peptide genes (porcine $\beta$-defensin (PBD) 1,PBD2, epididymis protein 2 splicing variant C (PEP2C), proline/arginine-rich peptide of 39 amino acids (PR39), protegrin (NPG) 1 and NPG3) and tight junction genes (claudin-1, claudin-2, occludin, zonula occludens-1 (ZO-1), and myosin light chain kinase (MLCK)) were measured by qPCR (CFX384; Bio-Rad). The primer information of these assayed genes and the housekeeping gene glyceraldehyde-3-phosphate dehydrogenase $(G A P D H)[21,22]$ are presented in Table S2. The $2^{- \text {ddCt }}$ method was used for quantification, with GAPDH as a reference gene [18].

\subsection{Pyrosequencing of Bacterial $16 S$ rRNA Gene Amplification}

Microbiota analyses of the cecum digesta samples were conducted as previously described [23]. Briefly, microbial genomic DNA was extracted from cecum digesta using the DNA stool mini kit (Tiangen, Beijing, China), according to the instructions of the manufacturer; a Nanodrop spectrophotometer was used to estimate DNA quantity and quality. The V3-V4 region of the bacterial $16 \mathrm{~S}$ ribosomal RNA gene was amplified with the primers 338F (5'-ACTCCTACGGGAGGCAGCA- $\left.{ }^{\prime}\right)$ and 806R (5'-GGACTACHVGGGTWVTAAT$\left.3^{\prime}\right)$ by PCR. The PCR products were separated by electrophoresis with a $1.5 \%$ agarose gel and separated and purified using the QIAquick Gel Extraction Kit (Qiagen, Germany). The purified products were sequenced using the Illumina Miseq platform (Personal Biotechnology Co., Ltd., Shanghai, China). The alpha diversity index (Chao1 index and observed OTUs), Jaccard distances for principal coordinate analysis (PCoA), and LDA effect Size (LEfSe) analysis were generated or calculated by personal genescloud (https:/ / www.genescloud.cn/home, accessed on 15 September 2021).

\subsection{Statistical Analyses}

Statistical analyses of microbial data were performed using GraphPad Prism (San Diego, CA, USA), and $p$-values were tested by Wilcoxon's rank-sum test. Data visualization was performed using R V.3.5.0 using the ggplot2 and corrplot packages. Other than that, statistical analyses were performed using SPSS version 13 (Chicago, IL, USA). Data are presented as mean $\pm \mathrm{SD}$. Levene's test of homogeneity of variance was used to evaluate the unequal variances before ANOVA analysis. Data were analyzed by one-way ANOVA, with a significance level of $p<0.05$, and tendency was set at $0.05 \leq p<0.10$; the Tukey-Kramer method was used for multiple mean comparisons. Welch's ANOVA was used in the case of unequal variances, followed by Dunnett's T3 test for post hoc comparisons.

\section{Results}

\subsection{Growth Performance}

The performance results are presented in Table 1. Compared to the control, OA1 significantly increased or tended to increase $(p<0.05$ or 0.10$)$ feed intake $(11.0 \%)$ and body weight gain (13.1\%) during days 1-14 and body weight gain (4.3\%) during days 1-49. Although OA2 did not affect $(p>0.10)$ the feed intake and body weight gain throughout the experiment, it significantly reduced or tended to reduce $(p<0.05$ or 0.10$)$ the feed/gain ratio $(2.1 \%)$ during days $15-49$ and the diarrhea rate (31.4-53.5\%) of piglets throughout the study compared to control. Interestingly, OA1 has worse results $(p<0.05)$ on the diarrhea rate $(37.1-96.6 \%)$, but it significantly had or tended to have better results $(p<0.05$ or 0.10$)$ on feed intake (5.6-10.8\%) and body weight gain (5.5-12.4\%) than OA2 throughout the 
experiment. No difference $(p>0.10)$ was found in the mortality rate among the three groups throughout the study.

Table 1. Effects of organic acids on growth performance and diarrhea rate ${ }^{1}$.

\begin{tabular}{|c|c|c|c|c|}
\hline & Control & OA1 & OA2 & $p$-Value \\
\hline \multicolumn{5}{|l|}{ Days 1-14 } \\
\hline Feed intake, kg/piglet & $2.92 \pm 0.25^{b}$ & $3.24 \pm 0.45^{\mathrm{a}}$ & $2.89 \pm 0.24^{b}$ & 0.02 \\
\hline $\begin{array}{l}\text { Body weight gain, } \\
\mathrm{kg} / \text { piglet }\end{array}$ & $1.68 \pm 0.17^{b}$ & $1.90 \pm 0.24^{\mathrm{a}}$ & $1.69 \pm 0.16^{b}$ & 0.02 \\
\hline Feed/gain ratio, kg/kg & $1.75 \pm 0.16$ & $1.71 \pm 0.18$ & $1.72 \pm 0.24$ & 0.88 \\
\hline Diarrhea rate, $\%$ & $10.2 \pm 3.1^{\mathrm{a}}$ & $9.6 \pm 2.9^{a}$ & $7.0 \pm 2.7^{b}$ & 0.03 \\
\hline Mortality rate, $\%$ & $0.83 \pm 2.89$ & $0.00 \pm 0.00$ & $1.67 \pm 3.89$ & 0.36 \\
\hline \multicolumn{5}{|l|}{ Days $15-49$} \\
\hline Feed intake, kg/piglet & $24.0 \pm 1.3^{\mathrm{a}, \mathrm{b}}$ & $24.4 \pm 1.7^{\mathrm{a}}$ & $23.1 \pm 1.3^{b}$ & 0.08 \\
\hline $\begin{array}{c}\text { Body weight gain, } \\
\mathrm{kg} / \text { piglet }\end{array}$ & $16.7 \pm 0.8$ & $17.3 \pm 1.2^{\#}$ & $16.4 \pm 1.0^{\#}$ & 0.13 \\
\hline Feed/gain ratio, $\mathrm{kg} / \mathrm{kg}$ & $1.43 \pm 0.05^{\#}$ & $1.41 \pm 0.05$ & $1.40 \pm 0.03^{\#}$ & 0.23 \\
\hline Diarrhea rate, $\%$ & $1.27 \pm 0.73^{\mathrm{a}}$ & $1.16 \pm 0.81^{\mathrm{a}}$ & $0.59 \pm 0.54^{b}$ & 0.05 \\
\hline Mortality rate, $\%$ & $0.83 \pm 2.89$ & $3.33 \pm 4.92$ & $2.50 \pm 4.52$ & 0.35 \\
\hline \multicolumn{5}{|l|}{ Days $1-49$} \\
\hline Feed intake, $\mathrm{kg}$ / piglet & $26.9 \pm 1.5^{\mathrm{a}, \mathrm{b}}$ & $27.7 \pm 1.9^{a}$ & $26.0 \pm 1.4^{b}$ & 0.05 \\
\hline $\begin{array}{l}\text { Body weight gain, } \\
\mathrm{kg} / \text { piglet }\end{array}$ & $18.4 \pm 0.9^{\mathrm{b}, \#}$ & $19.2 \pm 1.3^{a, \#}$ & $18.1 \pm 1.1^{b}$ & 0.06 \\
\hline Feed/gain ratio, $\mathrm{kg} / \mathrm{kg}$ & $1.46 \pm 0.05$ & $1.44 \pm 0.05$ & $1.43 \pm 0.04$ & 0.26 \\
\hline Diarrhea rate, $\%$ & $4.01 \pm 1.03^{\mathrm{a}}$ & $3.80 \pm 1.32^{\mathrm{a}}$ & $2.58 \pm 0.98^{b}$ & 0.01 \\
\hline Mortality rate, $\%$ & $1.67 \pm 3.89$ & $3.33 \pm 4.92$ & $4.17 \pm 6.69$ & 0.51 \\
\hline
\end{tabular}

${ }_{1}^{1}$ Values are means $\pm \mathrm{SD}, n=12$. Labeled means in a row with different letters differ, $p<0.05$. A given 2 means labeled with " indicates a tendency, $0.05 \leq p<0.10$.

\subsection{Serum Redox Status}

The serum redox status results are presented in Table 2. Compared to the control, OA1 tended to increase $(p<0.10)$ CAT activity $(25.6 \%)$, while OA2 tended to increase $(p<0.10)$ T-AOC activity $(30.4 \%)$ in the serum of piglets at day 14 . Interestingly, OA1 increased $(p<0.05)$ SOD activity by $13.5 \%$ and OA2 significantly increased or tended to increase $(p<0.05$ or 0.10$)$ both SOD and T-AOC activities in serum by $11.6-14.0 \%$, respectively, compared to control at day 49 . Notably, compared to control, both OA1 and OA2 reduced $(p<0.05)$ MDA concentrations by $35.7-45.7 \%$, respectively, in the serum of piglets at day 49 .

\subsection{Small Intestinal Histology and Chyme Digestive Enzyme Activity}

The small intestinal histology results are presented in Figure 1. The histopathology results showed that fragmentation of villi and slight vacuolar degeneration of epithelial cells were observed in the ileum (day 14) and jejunum (day 49) of the control group (Figure 1A,D, red arrow). Notably, the intestinal morphology results showed that OA2 tended to reduce $(p<0.10)$ crypt depth (Figure 1G) and significantly increased or tended to increase ( $p<0.05$ or 0.10 ) the ratio of villus height:crypt depth (Figure $1 \mathrm{H}$ ) in the duodenum at day 49 compared to those of the control and OA1. The chyme digestive enzyme activity results are presented in Table 3. The jejunal chyme $\alpha$-amylase, lipase, and neutral protease activities were not affected $(p>0.10)$ by both OA1 and OA2 at both days 14 and 49 . 
Table 2. Effects of organic acids on the serum antioxidant indexes ${ }^{1}$.

\begin{tabular}{|c|c|c|c|c|}
\hline & Control & OA1 & OA2 & $p$ value \\
\hline \multicolumn{5}{|l|}{ Day 14} \\
\hline T-AOC, U/L & $125 \pm 24^{b}$ & $150 \pm 36^{\mathrm{a}, \mathrm{b}}$ & $163 \pm 30.4^{\mathrm{a}}$ & 0.13 \\
\hline GPX, U/mL & $635 \pm 57$ & $594 \pm 49$ & $664 \pm 123$ & 0.36 \\
\hline $\mathrm{SOD}, \mathrm{U} / \mathrm{mL}$ & $37.6 \pm 4.0$ & $39.7 \pm 4.0$ & $40.7 \pm 4.7$ & 0.45 \\
\hline CAT, $\mathrm{U} / \mathrm{mL}$ & $3.9 \pm 1.2^{\#}$ & $4.9 \pm 0.3^{\#}$ & $5.2 \pm 2.4$ & 0.35 \\
\hline $\mathrm{MDA}, \mathrm{nmol} / \mathrm{mL}$ & $2.3 \pm 0.9$ & $2.7 \pm 0.7$ & $4.1 \pm 2.1$ & 0.13 \\
\hline $\begin{array}{c}\mathrm{PC}, \mathrm{nmol} / \mathrm{mL} \\
\text { Day } 49\end{array}$ & $1.3 \pm 0.8$ & $0.9 \pm 0.4$ & $1.2 \pm 0.4$ & 0.67 \\
\hline T-AOC, U/L & $189 \pm 22 \#$ & $197 \pm 26$ & $211 \pm 19^{\#}$ & 0.27 \\
\hline GPX, U/mL & $889 \pm 89$ & $908 \pm 45$ & $855 \pm 57$ & 0.40 \\
\hline $\mathrm{SOD}, \mathrm{U} / \mathrm{mL}$ & $41.4 \pm 1.0^{b}$ & $47.0 \pm 1.6^{\mathrm{a}}$ & $47.2 \pm 2.1^{\mathrm{a}}$ & 0.00 \\
\hline CAT, U/mL & $2.5 \pm 0.6$ & $2.7 \pm 1.0$ & $2.6 \pm 0.9$ & 0.93 \\
\hline $\mathrm{MDA}, \mathrm{nmol} / \mathrm{mL}$ & $7.0 \pm 1.1^{\mathrm{a}}$ & $3.8 \pm 1.8^{\mathrm{b}}$ & $4.5 \pm 1.5^{b}$ & 0.01 \\
\hline $\mathrm{PC}, \mathrm{nmol} / \mathrm{mL}$ & $0.5 \pm 0.2$ & $0.5 \pm 0.2$ & $0.4 \pm 0.2$ & 0.80 \\
\hline
\end{tabular}

${ }^{1}$ Values are means $\pm \mathrm{SD}, n=6$. Labeled means in a row with different letters differ, $p<0.05$. A given 2 means labeled with \# indicates a tendency, $0.05 \leq p<0.10$. T-AOC, total antioxidative capacity; GPX, glutathione peroxidase; $\mathrm{CAT}$, catalase; $\mathrm{SOD}$, superoxide dismutase; MDA, malondialdehyde; $\mathrm{PC}$, protein carbonyl.
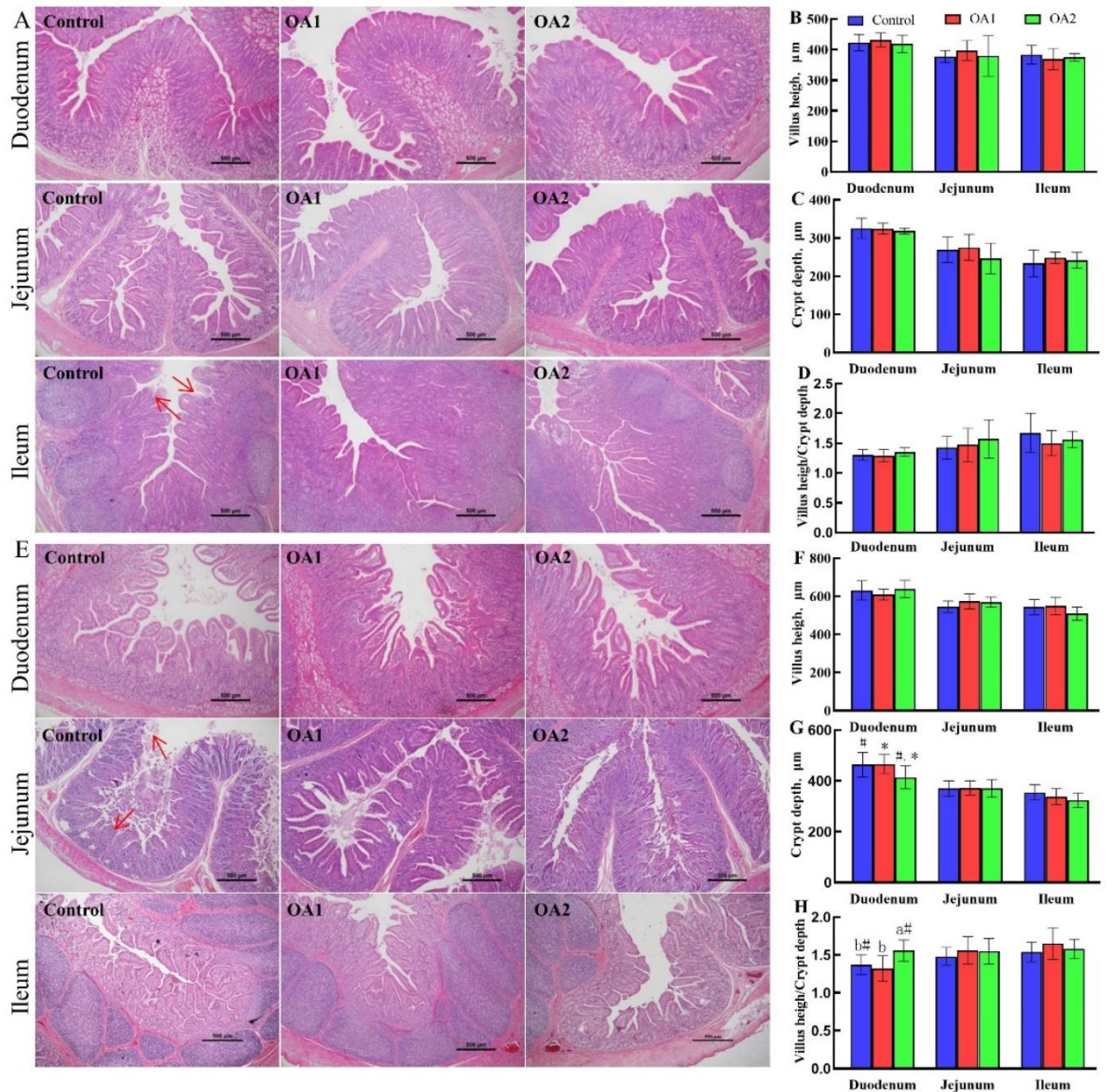

Figure 1. Effects of acidifiers on the gut morphology of the small intestine of piglets. The histopathology of the duodenum, jejunum, and ileum at day 14 (A) and day 49 (E). The morphology of villus height (B), crypt depth (C), and villus height/crypt depth (D) at day 14. The morphology of villus height (G), crypt depth (F), and villus height/crypt depth $(\mathbf{H})$ at day 49 . Values are means \pm SD, $n=6$. Labeled means in a row with different letters differ, $p<0.05$. A given 2 means labeled with \# indicates a tendency, $0.05 \leq p<0.10$. At the red arrow, the intestinal villi were broken off and the intestinal epithelial cells were denatured and necrotic. 
Table 3. Effects of organic acids on the digestive enzyme activity of jejunum chime ${ }^{1}$.

\begin{tabular}{ccccc}
\hline & Control & OA1 & OA2 & $p$-Value \\
\hline Day 14 & & & & \\
$\alpha$-amylase, U/g & $69.2 \pm 27.4$ & $88.7 \pm 22.2$ & $81.4 \pm 26.7$ & 0.47 \\
Lipase, U/g & $57.9 \pm 23.8$ & $66.7 \pm 23.0$ & $43.7 \pm 22.8$ & 0.26 \\
Neutral protease, U/g & $61.8 \pm 16.7$ & $73.5 \pm 13.8$ & $62.0 \pm 18.2$ & 0.39 \\
Day 49 & & & \\
$\alpha$-amylase, U/g & $27.0 \pm 12.4$ & $22.7 \pm 8.1$ & $25.5 \pm 15.0$ & 0.82 \\
Lipase, U/g & $46.3 \pm 19.6$ & $31.7 \pm 12.0$ & $30.8 \pm 5.8$ & 0.15 \\
Neutral protease, U/g & $46.2 \pm 15.0$ & $48.8 \pm 15.3$ & $40.3 \pm 18.0$ & 0.87 \\
\hline
\end{tabular}

${ }^{1}$ Values are means $\pm \mathrm{SD}, n=6$. Labeled means in a row without a common letter differ, $p<0.05$.

\subsection{Expression of Cytokine-, Tight Junction-, and Host Defense Peptide-Related Genes}

The effects of acidifiers on gene expression results are shown in Figure 2. Compared to the control, both OA1 and OA2 increased $(p<0.05)$ host defense peptides $(P B D 1, P B D 2$, $N P G 1$, and NPG3), while only OA2 decreased $(p<0.05)$ cytokines (IL-1 $\beta$ and IL-2) and increased $(p<0.05)$ tight junction genes (claudin-1) at the mRNA level in the jejunum at day 14. Notably, OA2 decreased $(p<0.05) I L-1 \beta, I L-2$, and NPG1, while it increased $(p<0.05)$ PBD2 at the mRNA level in the jejunum compared to OA1 at day 14 . At day 49, OA2 increased $(p<0.05)$ the mRNA abundance of PBD2 and NPG3 in the jejunum compared to those of the control and OA1.
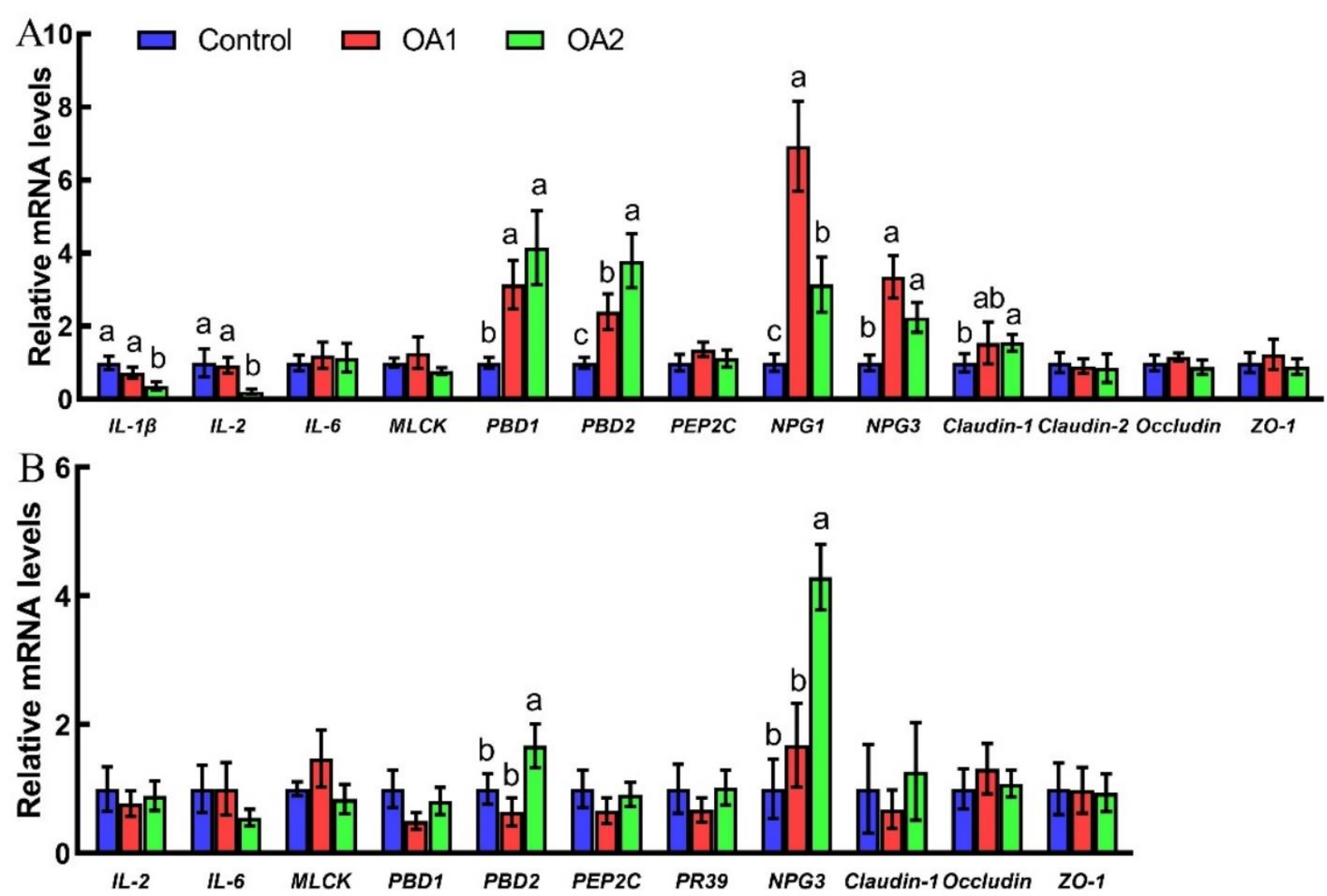

Figure 2. Effects of acidifiers on relative mRNA abundance of cytokines, tight junction genes, and defense peptides in the jejunum of piglets at day 14 (A) and day 49 (B). Values are means $\pm \mathrm{SD}, n=6$. Labeled means without a common letter differ, $p<0.05$. 


\subsection{Gut Microbiota}

The effects of acidifiers on gut microbiota are shown in Figures 3-6. The qualified sequences were clustered into amplicon sequence variants (ASVs) according to sequence similarity ( $>97 \%$; File S1). Interestingly, more ASVs were identified in the three groups, and the three diet groups shared 1734 ASVs at day 14 (Figure 3A) and 927 ASVs at day 49 (Figure $3 \mathrm{~B}$ ) in cecum chyme. From the analysis of taxonomic composition, both OA1 and OA2 altered the relative abundance of intestinal bacteria at both the phylum and genus levels. All the qualified sequences from the cecum chyme samples were then assigned to 25 known phyla (File S2). Of them, four phyla, Firmicutes, Bacteroidetes, Proteobacteria, and Spirochaetes, were predominantly found (Figure 4A,B). Moreover, 50 predominant genera were assigned from all the qualified sequences (File S3), and seven genera, including Lactobacillus, Prevotella, Faecalibacterium, Blautia, Phascolarctobacterium, Gemmiger, and Streptococcus, were predominantly found (Figure 4C,D).
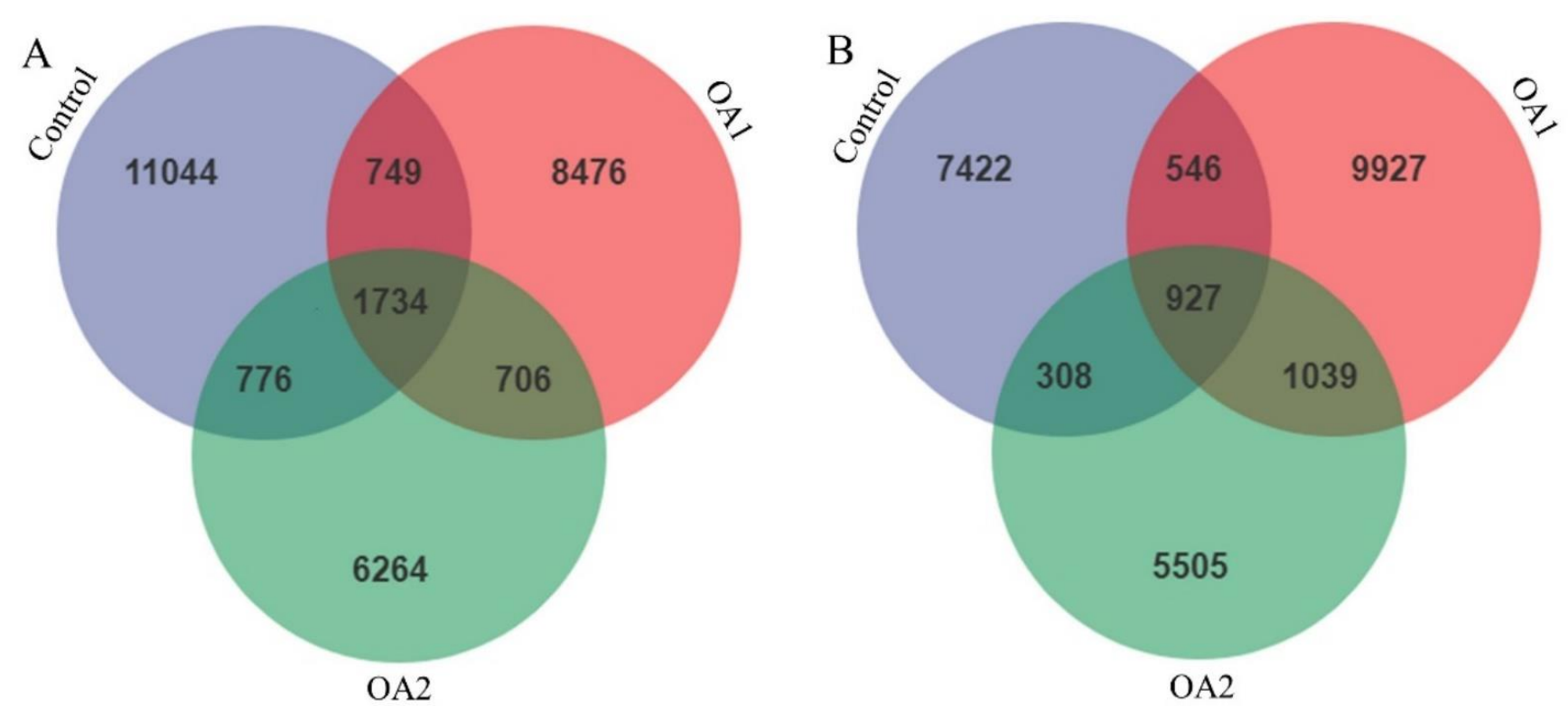

Figure 3. Number of identified ASVs in various comparisons in cecum chyme at day 14 (A) and day 49 (B). Each ellipse represents a treatment; the numbers in the diagrams represent how many ASVs are unique in the three groups and how many are shared as the areas intersect. ASVs, amplicon sequence variants. 

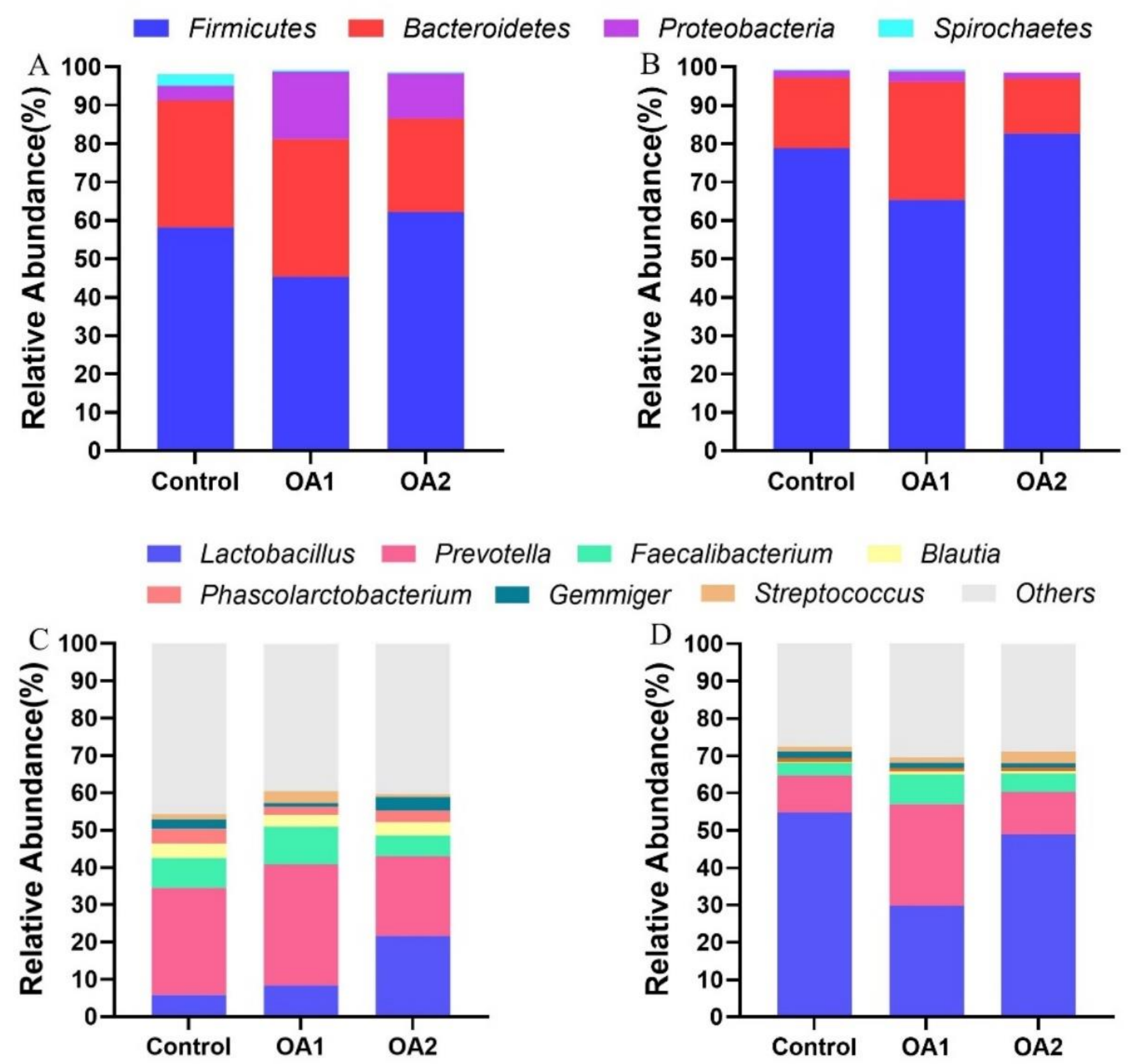

Faecalibacterium

\section{Blautia}

- Gemmiger
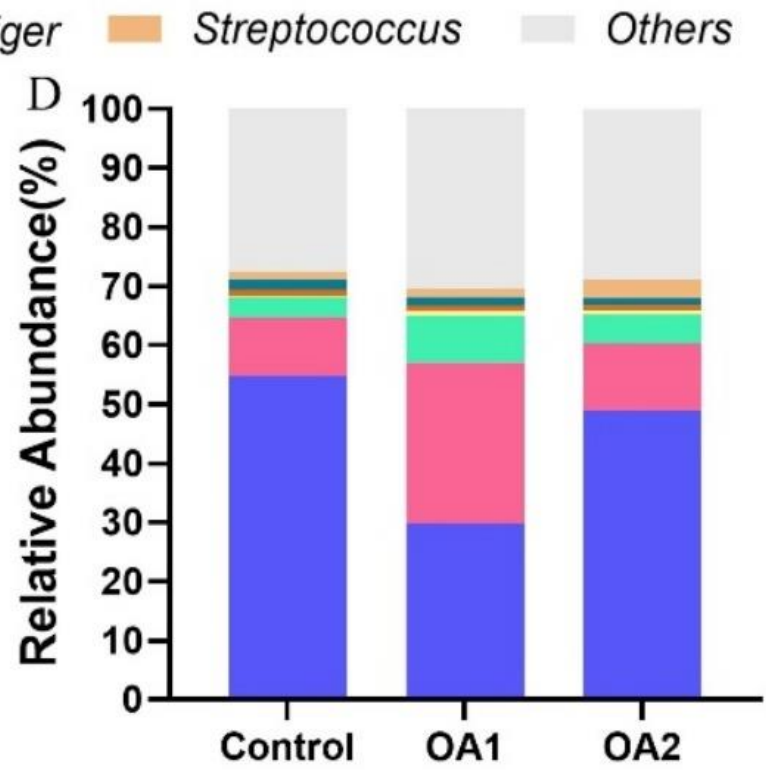

Figure 4. The analysis of composition of bacteria in cecum chyme. The phylum level of composition of bacteria at day 14 (A) and day 49 (B). The genus level of composition of bacteria at day 14 (C) and day 49 (D). The color-coded bar plot shows the relative abundance of bacterial phyla across the different groups. 
A

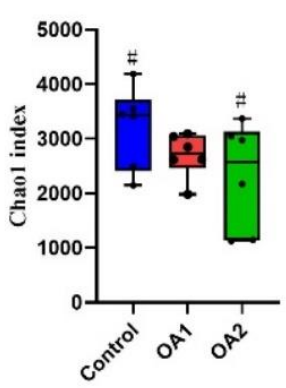

B

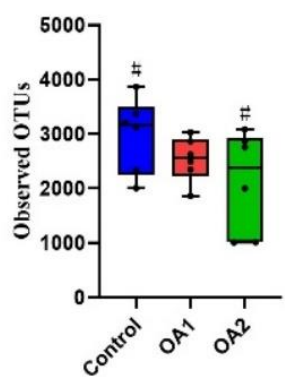
$\mathrm{C}$ Control OA1 O OA2
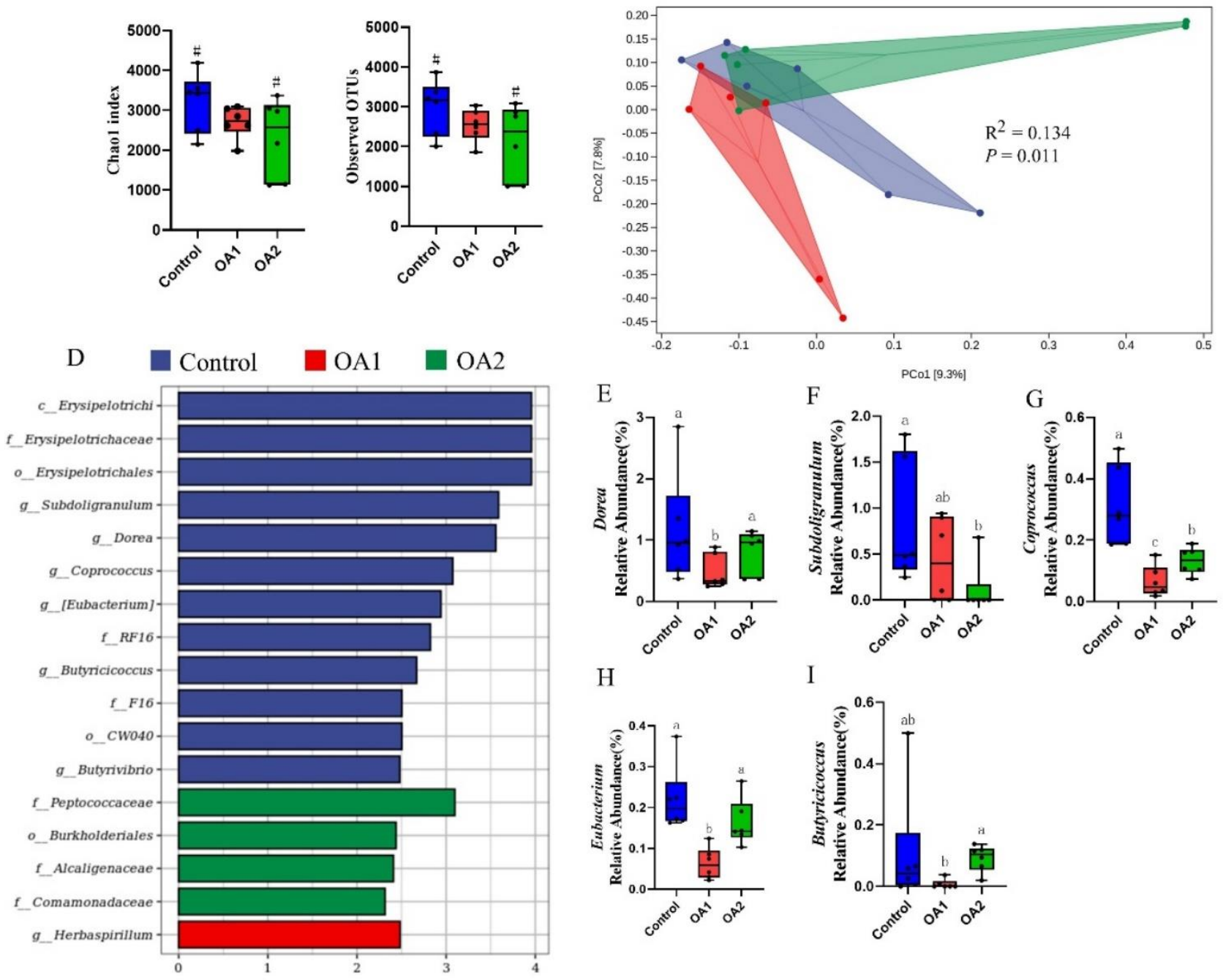

E

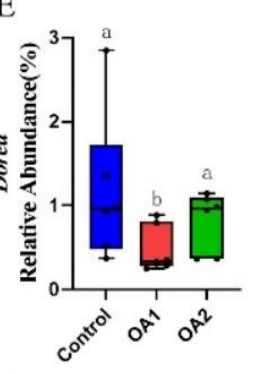

$\mathrm{F}$

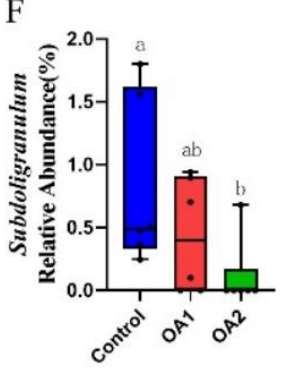

$\mathrm{G}$

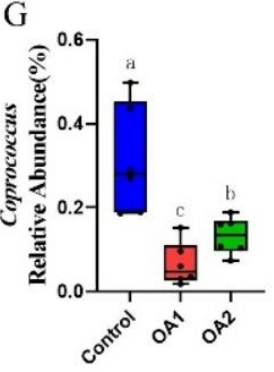

$\mathrm{H}$

I

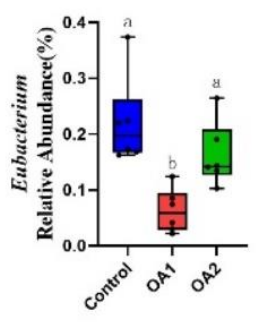

Figure 5. Gut microbiota analysis of cecum chyme at day 14. Comparison of alpha diversity index (Chao1 index and observed OTUs) among the three groups (A,B). Principal coordinates analysis (PCoA) based on Jaccard distances (C). Each point in the figure represents a sample, and different colored points indicate different groups. $p$-values were tested by permutational multivariate analysis of variance (Adonis). LEfSe analysis effect size identified the most differentially abundant taxa in the cecal chyme microbiota community of the three groups, and only taxonomies of LDA score $>2$ are shown (D). Relative abundances of Dorea, Subdoligranulum, Coprococcus, Eubacterium, and Butyricicoccus among the three groups (E-I). Labeled means with different superscript letters are significantly different $(p \leq 0.05)$ and with ${ }^{\#}$ indicates a tendency $(0.05 \leq p<0.10)$ by Wilcoxon's rank-sum test $(n=6)$. LDA, linear discriminant analysis. 

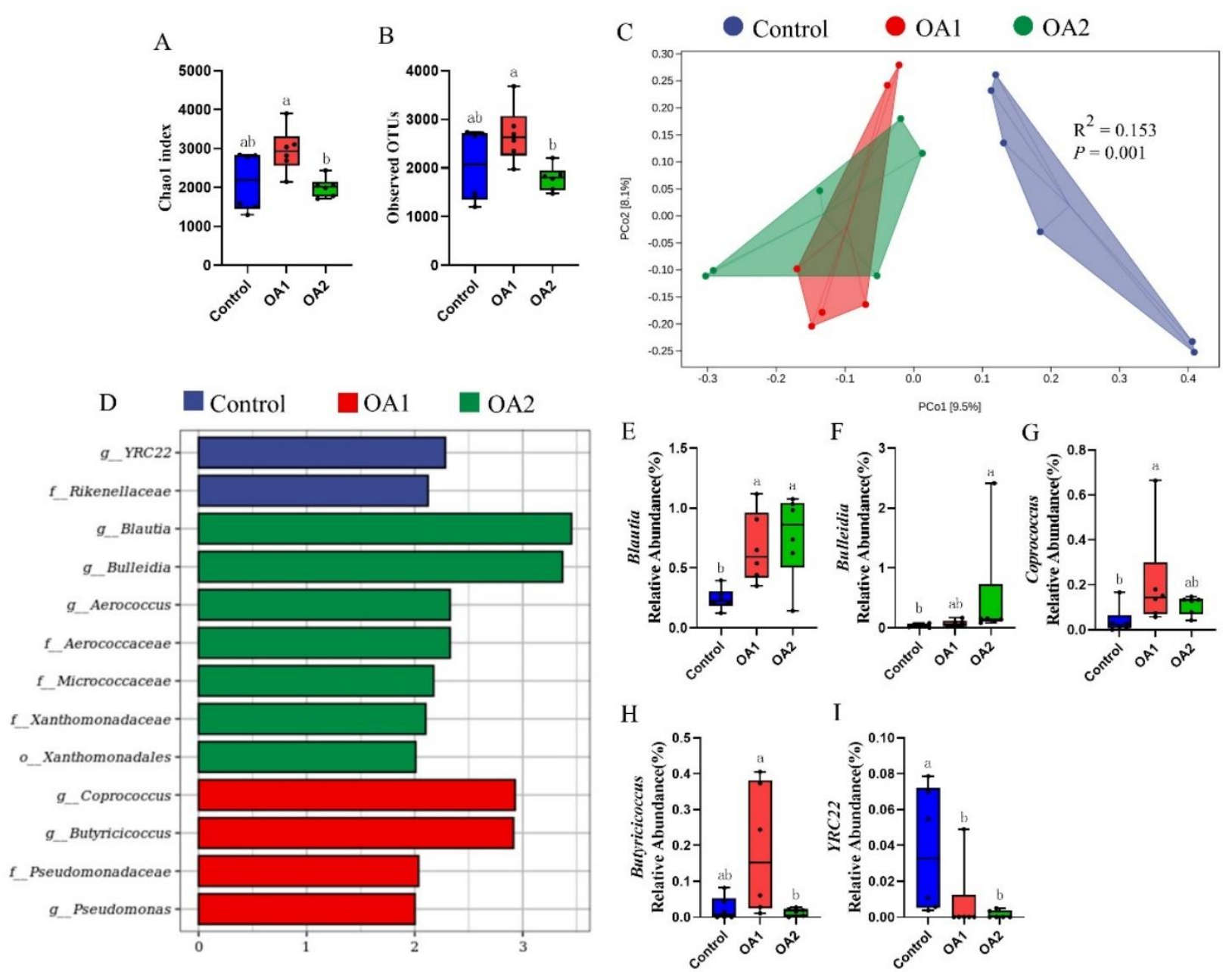

Figure 6. Gut microbiota analysis of cecum chyme at day 49. Comparison of alpha diversity index (Chao1 index and observed OTUs) among three groups (A,B). Principal coordinates analysis (PCoA) based on Jaccard distances (C). Each point in the figure represents a sample, and different colored points indicate different groups. $p$-values were tested by permutational multivariate analysis of variance (Adonis). LEfSe analysis effect size identified the most differentially abundant taxa in the cecal chyme microbiota community of the three groups, and only taxonomies of LDA score $>2$ are shown (D). Relative abundances of Blautia, Bulleidia, Coprococcus, Butyricicoccus, and YRC22 among the three groups (E-I). Labeled means with different superscript letters are significantly different $(p \leq 0.05)$ by Wilcoxon's rank-sum test $(n=6)$. LDA, linear discriminant analysis.

At day 14, the alpha diversity index (Chao1 index and observed OTUs) for the microbiome analysis of OA2 tended to decrease $(p<0.10)$ when compared to the control (Figure $5 \mathrm{~A}, \mathrm{~B})$. Interestingly, the alpha diversity index of OA1 was higher $(p<0.05)$ than of OA2 (Figure 6A,B) at day 49. The results of principal coordinates analysis using Jaccard distances showed that the control was differentiated $(p=0.011)$ at day 14 (Figure $5 \mathrm{C}$ ) and was greatly $(p=0.001)$ differentiated at day 49 (Figure $6 \mathrm{C}$ ) compared to those of OA1 or OA2.

To identify which bacterial taxa were distinctly different among the three groups, LEfSe analysis with LDA scores $>2$ was used. The results identified 12 discriminative features in the microbiota of the control, 1 in OA1, and 4 in OA2 at day 14 (Figure 5D) and identified 2 in the control, 4 in OA1, and 7 in OA2 at day 49 (Figure 6D). Moreover, at day 14 , the abundance comparisons of predominant genera revealed that Dorea, Coprococcus, and Eubacterium in OA1 were significantly reduced $(p<0.05)$, whereas Subdoligranulum and Coprococcus in OA2 were greatly decreased $(p<0.05)$ when compared to the control (Figure 5E-I). However, at day 49, Coprococcus and Blautia in OA1 and Blautia and Bulleidia 
in OA2 were significantly increased $(p<0.05)$, whereas $Y R C 22$ in OA1 and OA2 were greatly decreased $(p<0.05)$ when compared to the control (Figure $6 \mathrm{E}-\mathrm{I}$ ).

\section{Discussion}

The current study shows that drinking water supplementation of organic acids can improve the performance of weanling pigs. Specifically, OA1 significantly increased or tended to increase feed intake and body weight gain of piglets during days 1-14 and $1-49$, while OA2 significantly reduced or tended to reduce the feed/gain ratio during days $15-49$ and the diarrhea rate throughout the study. These outcomes are similar to previous studies, which have reported that organic acids alone or in combination can improve the performance of weanling pigs [7,11,24,25], chickens [26-28], and rabbits [29]. The beneficial effects of these organic acids on the performance of animals have been associated with their ability to reduce digesta $\mathrm{pH}$ value, thus improving the antibiotics' roles and digestive enzyme activities in the gastrointestinal tract [7,11,24-29]. Notably, OA1 displayed better ability in the improvement of feed intake and body weight gain, while OA2 exerted a better ability to increase feed conversion efficiency and decrease the diarrhea rate. These discrepancies could be due to the different composition of the two acidifiers and their acidification capacity of OA1 ( $\mathrm{pH} 4.21$ ) and OA2 ( $\mathrm{pH} 4.88$ ) to the drinking water [30].

Redox imbalance is usually triggered by early weanling stress, resulting in organ damage and disease susceptibility in weanling piglets [3,31-34]. Interestingly, both of the two organic acid blends significantly improved or tended to improve the redox status, including the enhancement of the serum T-AOC, SOD, and/or CAT activities of piglets. This may be owed to the piglets ingesting acidifiers containing formic acid, acetic acid, propionic acid, butyric acid, lactic acid, citric acid and/or sorbic acid, which have a function in maintaining redox homeostasis in animals [35-37].

The gastrointestinal tract is particularly susceptible to weanling stress, which can impair gastrointestinal morphology, permeability, and function [38]. Notably, both of the acidifiers prevented the fragmentation of villi, and slight vacuolar degeneration of epithelial cells in the ileum (day 14) and jejunum (day 49) were observed in the control group. Meanwhile, OA2 significantly reduced or tended to reduce crypt depth and increased the ratio of villus height:crypt depth in the duodenum at day 49 compared to those of the control and OA1. These outcomes are in agreement with previous studies, which showed organic acids can improve intestinal morphology [39]. Although digestive enzyme activities were not affected by the two organic acid blends, they were reduced at day 49 compared to those on day 14 . This might be due to the piglets ingesting more feed; thus, these digestive enzyme activities were diluted by chyme from the jejunum [40]. Moreover, the two acidifiers, OA1 and/or OA2, decreased pro-inflammatory cytokines (IL-1 $\beta$ and $I L-2)[41,42]$ and increased host defense peptides (PBD1, PBD2, NPG1, and NPG3) $[43,44]$ and tight junction (claudin-1) gene expression at the mRNA level in the jejunum at day 14 and 49 compared to those of the control. Notably, OA2 decreased IL-1 $\beta$ and IL-2 while increasing PBD2 and NPG3 at the mRNA level in the jejunum compared to OA1 at days 14 and/or 49. These results could explain why the two acidifiers have better intestinal morphology than those of the control and why the OA2 group is better than the OA1 group. The chyme digestive enzyme activities were not affected by the two acidifiers, which was inconsistent with the previous report [45]. This discrepancy might be due to the different animal species, physiological stages, dietary structure, and composition of acidifiers [38,46].

Since gut microbes also play an active role in maintaining the intestinal health of weanling pigs [38,47,48], 16S rRNA gene sequencing technology was used to analyze and compare the cecal microbiota composition of the weaned pigs. Compared with the control, the abundance of predominant genera of Blautia was increased and YRC22 was decreased in both OA1 and OA2, while Dorea and Eubacterium in OA1 and Subdoligranulum in OA2 were decreased and Bulleidia in OA2 was increased at days 14 and/or 49. Blautia plays the roles of an antibacterial agent and alleviating inflammatory disease characteristics [49], and 
Dorea can metabolize mucin and induce pro-inflammatory cytokines [50]; thus, increasing Blautia and decreasing Dorea by OA1 and/or OA2 may improve the immunity status of the gut of piglets. Eubacterium and Subdoligranulum can produce butyrate, which plays a critical role in energy homeostasis and immunomodulation in the gut $[51,52]$. Strikingly, these genera were decreased in OA1 or OA2, which might be due to an adaptation mechanism where the piglets have already ingested adequate organic acids with similar functions from their drinking water, thus suppressing the growth of these genera $[12,53]$. Since Bulleidia is a hyperglycemia-associated bacterial genus [54] and the function of $Y R C 22$ is unknown [55], the effects of changes of these bacteria by OA1 and OA2 are unknown. Strikingly, Coprococcus can also produce butyrate [56], but it is hard for us to explain why Coprococcus was decreased in both OA1 and OA2 at day 14, while it was increased in OA2 at day 49 compared to those of the control. Therefore, its role in organic-acid-mediated gastrointestinal health needs to be further explored.

\section{Conclusions}

In summary, the current study has illustrated that drinking water supplementation of both organic acid blends can improve the performance and health status of weanling pigs, as further evidenced by improvement of redox homeostasis and gastrointestinal morphology. The protective mechanisms of these two organic acids against weanling stress in piglets are associated with (1) the regulation of cytokines and host defense peptides and tight junction gene expression in the jejunum; and (2) maintaining the balance of microflora in the intestine.

Supplementary Materials: The following are available online at https://www.mdpi.com/article/ 10.3390/antiox10111665/s1. Table S1: Basal diet composition and nutrient level; Table S2: List of primers used for Q-PCR analysis; File S1: Amplicon sequence variants; File S2: Phylum level composition of bacteria; File S3: Genus level composition of bacteria.

Author Contributions: L.-H.S., Y.-M.H. and Y.-Y.W. designed the research; X.-D.X., H.S. and Z.-C.D. conducted the experiments and analyzed the data; L.W., Y.-W.W. and J.-G.L. provided resources for the study; Z.-C.D., X.-D.X., L.W., Y.-W.W., J.-G.L. and L.-H.S. wrote the paper; L.-H.S. has the primary responsibility for the final content. All authors have read and agreed to the published version of the manuscript.

Funding: This research was supported by a research gift from Trouw Nutrition.

Institutional Review Board Statement: This research was approved by the Scientific Ethics Committee of Huazhong Agricultural University on 16 August 2020. The project identification code is HZAUSW-2020-0004.

Informed Consent Statement: Not applicable.

Data Availability Statement: Data are contained within the article.

Conflicts of Interest: X.-D.X., Z.-C.D., Y.-W.W., H.S., L.W., G.-J.L. and L.-H.S., no conflict of interest; Y.-M.H. and Y.-Y.W. are members of Trouw Nutrition.

\section{References}

1. Laine, T.M.; Lyytikainen, T.; Yliaho, M.; Anttila, M. Risk factors for post-weaning diarrhoea on piglet producing farms in Finland. Acta Vet. Scand. 2008, 50, 20. [CrossRef] [PubMed]

2. Yang, Y.; Lee, K.Y.; Kim, I.H. Effects of dietary protected organic acids on growth performance, nutrient digestibility, fecal microflora, diarrhea score, and fecal gas emission in weanling pigs. Can J. Anim. Sci. 2019, 99, 514-520. [CrossRef]

3. Wang, T.X.; Yao, W.L.; Li, J.; Shao, Y.F.; He, Q.Y.; Xia, J.; Huang, F.R. Dietary garcinol supplementation improves diarrhea and intestinal barrier function associated with its modulation of gut microbiota in weaned piglets. J. Anim. Sci. Biotechnol. 2020, 11, 12. [CrossRef]

4. Luise, D.; Bertocchi, M.; Motta, V.; Salvarani, C.; Bosi, P.; Luppi, A.; Fanelli, F.; Mazzoni, M.; Archetti, I.; Maiorano, G.; et al. Bacillus sp. probiotic supplementation diminish the Escherichia coli F4ac infection in susceptible weaned pigs by influencing the intestinal immune response, intestinal microbiota and blood metabolomics. J. Anim. Sci. Biotechnol. 2019, 10, 74. [CrossRef] [PubMed] 
5. Suiryanrayna, M.V.A.N.; Ramana, J.V. A review of the effects of dietary organic acids fed to swine. J. Anim. Sci. Biotechnol. 2015, 6 , 45. [CrossRef] [PubMed]

6. Pluske, J.R. Feed- and feed additives-related aspects of gut health and development in weanling pigs. J. Anim. Sci. Biotechnol. 2013, 4, 1-7. [CrossRef]

7. Han, Y.S.; Tang, C.H.; Zhao, Q.Y.; Zhan, T.F.; Zhang, K.; Han, Y.M.; Zhang, J.M. Effects of dietary supplementation with combinations of organic and medium chain fatty acids as replacements for chlortetracycline on growth performance, serum immunity, and fecal microbiota of weaned piglets. Livest Sci. 2018, 216, 210-218. [CrossRef]

8. Degroote, J.; Vergauwen, H.; Van Noten, N.; Wang, W.; De Smet, S.; Van Ginneken, C.; Michiels, J. The Effect of Dietary Quercetin on the Glutathione Redox System and Small Intestinal Functionality of Weaned Piglets. Antioxidants 2019, 8, 312. [CrossRef]

9. Grilli, E.; Tugnoli, B.; Passey, J.L.; Stahl, C.H.; Piva, A.; Moeser, A.J. Impact of dietary organic acids and botanicals on intestinal integrity and inflammation in weaned pigs. BMC Vet. Res. 2015, 11, 96. [CrossRef]

10. Huang, C.; Song, P.X.; Fan, P.X.; Hou, C.L.; Thacker, P.; Ma, X. Dietary Sodium Butyrate Decreases Postweaning Diarrhea by Modulating Intestinal Permeability and Changing the Bacterial Communities in Weaned Piglets. J. Nutr. 2015, 145, 2774-2780 [CrossRef]

11. Long, S.F.; Xu, Y.T.; Pan, L.; Wang, Q.Q.; Wang, C.L.; Wu, J.Y.; Wu, Y.Y.; Han, Y.M.; Yun, C.H.; Piao, X.S. Mixed organic acids as antibiotic substitutes improve performance, serum immunity, intestinal morphology and microbiota for weaned piglets. Anim. Feed Sci. Technol. 2018, 235, 23-32. [CrossRef]

12. Luise, D.; Correa, F.; Bosi, P.; Trevisi, P. A Review of the Effect of Formic Acid and Its Salts on the Gastrointestinal Microbiota and Performance of Pigs. Animals 2020, 10, 887. [CrossRef]

13. Partanen, K.H.; Mroz, Z. Organic acids for performance enhancement in pig diets. Nutr. Res. Rev. 1999, 12, 117-145. [CrossRef]

14. Oleskin, A.V.; Shenderov, B.A. Microbial Communication and Microbiota-Host Interactions: Biomedical, Biotechnological, and Biopolitical Implications; Nova Science Publishers: Hauppauge, NY, USA, 2020.

15. Oleskin, A.V.; Shenderov, B.A.; Rogovsky, V.S. Role of Neurochemicals in the Interaction between the Microbiota and the Immune and the Nervous System of the Host Organism. Probiotics Antimicrob. Proteins 2017, 9, 215-234. [CrossRef]

16. Oleskin, A.V.; Shenderov, B.A. Neuromodulatory effects and targets of the SCFAs and gasotransmitters produced by the human symbiotic microbiota. Microb. Ecol. Health Dis. 2016, 27, 30971. [CrossRef] [PubMed]

17. Sofos, J.N.; Pierson, M.D.; Blocher, J.C.; Busta, F.F. Mode of Action of Sorbic Acid on Bacterial-Cells and Spores. Int. J. Food Microbiol. 1986, 3, 1-17. [CrossRef]

18. Zhao, L.; Deng, J.; Xu, Z.J.; Zhang, W.P.; Khalil, M.M.; Karrow, N.A.; Sun, L.H. Mitigation of Aflatoxin B1 Hepatoxicity by Dietary Hedyotis diffusa Is Associated with Activation of NRF2/ARE Signaling in Chicks. Antioxidants 2021, 10, 878. [CrossRef] [PubMed]

19. Sun, L.H.; Zhang, N.Y.; Zhu, M.K.; Zhao, L.; Zhou, J.C.; Qi, D.S. Prevention of Aflatoxin B1 Hepatoxicity by Dietary Selenium Is Associated with Inhibition of Cytochrome P450 Isozymes and Up-Regulation of 6 Selenoprotein Genes in Chick Liver. J. Nutr. 2015, 146, 655-661. [CrossRef] [PubMed]

20. Zhang, J.C.; Chen, P.; Zhang, C.; Khalil, M.M.; Zhang, N.Y.; Qi, D.S.; Wang, Y.W.; Sun, L.H. Yeast culture promotes the production of aged laying hens by improving intestinal digestive enzyme activities and the intestinal health status. Poult. Sci. 2020, 99, 2026-2032. [CrossRef]

21. Kim, K.; He, Y.; Xiong, X.; Ehrlich, A.; Li, X.; Raybould, H.; Atwill, E.R.; Maga, E.A.; Jørgensen, J.; Liu, Y. Dietary supplementation of Bacillus subtilis influenced intestinal health of weaned pigs experimentally infected with a pathogenic E. coli. J. Anim. Sci. Biotechnol. 2019, 10, 52. [CrossRef]

22. Li, Q.; Domig, K.J.; Ettle, T.; Windisch, W.; Mair, C.; Schedle, K. Evaluation of potential reference genes for relative quantification by RT-qPCR in different porcine tissues derived from feeding studies. Int. J. Mol. Sci. 2011, 12, 1727-1734. [CrossRef]

23. Liu, M.; Zhang, L.; Chu, X.H.; Ma, R.; Wang, Y.W.; Liu, Q.; Zhang, N.Y.; Karrow, N.A.; Sun, L.H. Effects of deoxynivalenol on the porcine growth performance and intestinal microbiota and potential remediation by a modified HSCAS binder. Food Chem. Toxicol. 2020, 141, 111373. [CrossRef]

24. Li, Z.; Yi, G.; Yin, J.; Sun, P.; Li, D.; Knight, C. Effects of organic acids on growth performance, gastrointestinal pH, intestinal microbial populations and immune responses of weaned pigs. Asian-Australas J. Anim. Sci. 2008, 21, 252-261. [CrossRef]

25. Overland, M.; Kjos, N.P.; Borg, M.; Skjerve, E.; Sorum, H. Organic acids in diets for entire male pigs: Effect on skatole level, microbiota in digesta, and growth performance. Livest Sci. 2008, 115, 169-178. [CrossRef]

26. Nguyen, D.H.; Kim, I.H. Protected Organic Acids Improved Growth Performance, Nutrient Digestibility, and Decreased Gas Emission in Broilers. Animals 2020, 10, 416. [CrossRef] [PubMed]

27. Kumar, A.; Toghyani, M.; Kheravii, S.K.; Pineda, L.; Han, Y.; Swick, R.A.; Wu, S.B. Potential of blended organic acids to improve performance and health of broilers infected with necrotic enteritis. Anim. Nutr. 2021, 7, 440-449. [CrossRef]

28. Dai, D.; Qiu, K.; Zhang, H.J.; Wu, S.G.; Han, Y.M.; Wu, Y.Y.; Qi, G.H.; Wang, J. Organic Acids as Alternatives for Antibiotic Growth Promoters Alter the Intestinal Structure and Microbiota and Improve the Growth Performance in Broilers. Front. Microbiol. 2021, 11, 618144. [CrossRef]

29. Zhu, K.H.; Xu, X.R.; Sun, D.F.; Tang, J.L.; Zhang, Y.K. Effects of drinking water acidification by organic acidifier on growth performance, digestive enzyme activity and caecalbacteria in growing rabbits. Anim. Feed Sci. Technol. 2014, 190, 87-94. [CrossRef] 
30. Van Bunnik, B.A.D.; Hagenaars, T.J.; Bolder, N.M.; Nodelijk, G.; de Jong, M.C.M. Interaction effects between sender and receiver processes in indirect transmission of Campylobacter jejuni between broilers. BMC Vet. Res. 2012, 8, 123. [CrossRef] [PubMed]

31. Xu, C.C.; Yang, S.F.; Zhu, L.H.; Cai, X.; Sheng, Y.S.; Zhu, S.W.; Xu, J.X. Regulation of N-acetyl cysteine on gut redox status and major microbiota in weaned piglets. J. Anim. Sci. 2014, 92, 1504-1511. [CrossRef]

32. Vergauwen, H.; Degroote, J.; Prims, S.; Wang, W.; Fransen, E.; De Smet, S.; Casteleyn, C.; Van Cruchten, S.; Michiels, J.; Van Ginneken, C. Artificial rearing influences the morphology, permeability and redox state of the gastrointestinal tract of low and normal birth weight piglets. J. Anim. Sci. Biotechnol. 2017, 8, 30. [CrossRef]

33. Wen, C.Y.; Li, F.N.; Guo, Q.P.; Zhang, L.Y.; Duan, Y.H.; Wang, W.L.; Li, J.Z.; He, S.P.; Chen, W.; Yin, Y.L. Protective effects of taurine against muscle damage induced by diquat in 35 days weaned piglets. J. Anim. Sci. Biotechnol. 2020, 11, 56. [CrossRef]

34. Corino, C.; Prost, M.; Pizzi, B.; Rossi, R. Dietary Plant Extracts Improve the Antioxidant Reserves in Weaned Piglets. Antioxidants 2021, 10, 702. [CrossRef] [PubMed]

35. Milton, J.J.; Roger, B.; Sabine, S.; Miriam, H.; Waldiceu, V.; Ana, P. Ingestion of organic acids and cinnamaldehyde improves tissue homeostasis of piglets exposed to enterotoxic Escherichia coli (ETEC). J. Anim. Sci. 2020, 98, skaa012.

36. Chen, J.; Guo, J.; Guan, W.T.; Song, J.J.; Deng, Z.X.; Cheng, L.; Deng, Y.L.; Chen, F.; Zhang, S.H.; Zhang, Y.Z.; et al. Effect of pad-fan cooling and dietary organic acid supplementation during late gestation and lactation on reproductive performance and antioxidant status of multiparous sows in hot weather. Trop. Anim. Health Prod. 2018, 50, 973-982. [CrossRef] [PubMed]

37. Wang, J.; Dai, D.; Zhang, H.J.; Wu, S.G.; Han, Y.M.; Wu, Y.Y.; Qi, G.H. Organic acids modulate systemic metabolic perturbation caused by salmonella pullorum challenge in early-stage broilers. Front. Physiol. 2019, 10, 1418. [CrossRef]

38. Sun, X.; Cui, Y.; Su, Y.; Gao, Z.; Diao, X.; Li, J.; Zhu, X.; Li, D.; Li, Z.; Wang, C.; et al. Dietary Fiber Ameliorates LipopolysaccharideInduced Intestinal Barrier Function Damage in Piglets by Modulation of Intestinal Microbiome. Msystems 2021, 6, e01374-20. [CrossRef] [PubMed]

39. Moeser, A.J.; Pohl, C.S.; Rajput, M. Weaning stress and gastrointestinal barrier development: Implications for lifelong gut health in pigs. Anim. Nutr. 2017, 3, 313-321. [CrossRef]

40. Zhang, Z.; Jiang, Z.; Lin, Y.; Zheng, L.; Yu, D. Effect of Stress From Early Weaning Pig on Its Digestive Enzymes Activity. Chin. J. Anim. Husb. 1999, 35, 6-8.

41. Xu, Y.T.; Lahaye, L.; He, Z.X.; Zhang, J.X.; Yang, C.B.; Piao, X.S. Micro-encapsulated essential oils and organic acids combination improves intestinal barrier function, inflflammatory responses and microbiota of weaned piglets challenged with enterotoxigenic Escherichia coli F4(K88+). Anim. Nutr. 2020, 6, 269-277. [CrossRef]

42. Jackman, J.A.; Boyd, R.D.; Elrod, C.C. Medium-chain fatty acids and monoglycerides as feed additives for pig production: Towards gut health improvement and feed pathogen mitigation. J. Anim. Sci. Biotechnol. 2020, 11, 44. [CrossRef]

43. Wang, J.; Huang, N.N.; Xiong, J.; Wei, H.K.; Jiang, S.W.; Peng, J. Caprylic acid and nonanoic acid upregulate endogenous host defense peptides to enhance intestinal epithelial immunological barrier function via histone deacetylase inhibition. Int. Immunopharmacol. 2018, 65, 303-311. [CrossRef]

44. Zhou, Z.Z.; Huang, J.; Hao, H.H.; Wei, H.K.; Zhou, Y.F.; Peng, J. Applications of new functions for inducing host defense peptides and synergy sterilization of medium chain fatty acids in substituting in-feed antibiotics. J. Funct. Foods 2019, 52, 348-359. [CrossRef]

45. Xu, Y.T.; Liu, L.; Long, S.F.; Pan, L.; Piao, X.S. Effect of organic acids and essential oils on performance, intestinal health and digestive enzyme activities of weaned pigs. Anim. Feed Sci. Technol. 2018, 235, 110-119. [CrossRef]

46. Qiu, Y.Q.; Liu, S.L.; Hou, L.; Li, K.B.; Wang, L.; Gao, K.G.; Yang, X.F.; Jiang, Z.Y. Supplemental Choline Modulates Growth Performance and Gut Inflammation by Altering the Gut Microbiota and Lipid Metabolism in Weaned Piglets. J. Nutr. 2021, 151, 20-29. [CrossRef]

47. Wang, J.; Han, Y.; Meng, F.; Zhao, J.; Zhou, Z.; Fan, H. Fecal microbiota succession of piglets from birth to post-weaning by 454 pyrosequencing analysis. Trans. Tianjin Univ. 2017, 23, 211-220. [CrossRef]

48. Guevarra, R.B.; Hong, S.H.; Cho, J.H.; Kim, B.R.; Shin, J.; Lee, J.H.; Kang, B.N.; Kim, Y.H.; Wattanaphansak, S.; Isaacson, R.E.; et al. The dynamics of the piglet gut microbiome during the weaning transition in association with health and nutrition. J. Anim. Sci. Biotechnol. 2018, 9, 54. [CrossRef] [PubMed]

49. Liu, X.M.; Mao, B.Y.; Gu, J.Y.; Wu, J.Y.; Cui, S.M.; Wang, G.; Zhao, J.X.; Zhang, H.; Chen, X. Blautia-a new functional genus with potential probiotic properties? Gut Microbes 2021, 13, 1-21. [CrossRef] [PubMed]

50. Shahi, S.K.; Freedman, S.N.; Mangalam, A.K. Gut microbiome in multiple sclerosis: The players involved and the roles they play. Gut Microbes 2017, 8, 607-615. [CrossRef] [PubMed]

51. Polansky, O.; Sekelova, Z.; Faldynova, M.; Sebkova, A.; Sisak, F.; Rychlik, I. Important Metabolic Pathways and Biological Processes Expressed by Chicken Cecal Microbiota. J. Appl. Environ. Microbiol. 2016, 82, 1569-1576. [CrossRef] [PubMed]

52. Mukherjee, A.; Lordan, C.; Ross, R.P.; Cotter, P.C. Gut microbes from the phylogenetically diverse genus Eubacterium and their various contributions to gut health. Gut Microbes 2020, 12, 28. [CrossRef] [PubMed]

53. Tugnoli, B.; Giovagnoni, G.; Piva, A.; Grilli, E. From Acidifiers to Intestinal Health Enhancers: How Organic Acids Can Improve Growth Efficiency of Pigs. Animals 2020, 10, 134. [CrossRef] [PubMed]

54. Wang, R.R.; Xu, Y.S.; Ji, M.M.; Zhang, L.; Li, D.; Lang, Q.; Zhang, L.; Ji, G.; Liu, B.C. Association of the oral microbiome with the progression of impaired fasting glucose in a Chinese elderly population. J. Oral Microbiol. 2019, 11, 1605789. [CrossRef] [PubMed] 
55. Patra, A.K.; Park, T.; Braun, H.S.; Geiger, S.; Pieper, R.; Yu, Z.T.; Aschenbach, J.R. Dietary Bioactive Lipid Compounds Rich in Menthol Alter Interactions Among Members of Ruminal Microbiota in Sheep. Front. Microbiol. 2019, 10, 2038. [CrossRef] [PubMed]

56. Riviere, A.; Selak, M.; Lantin, D.; Leroy, F.; De Vuyst, L. Bifidobacteria and Butyrate-Producing Colon Bacteria: Importance and Strategies for Their Stimulation in the Human Gut. Front. Microbiol. 2016, 7, 979. [CrossRef] 